\title{
The Use of Portable Interpreting Devices: An Overview
}

\author{
Rafael Porlán Moreno
}

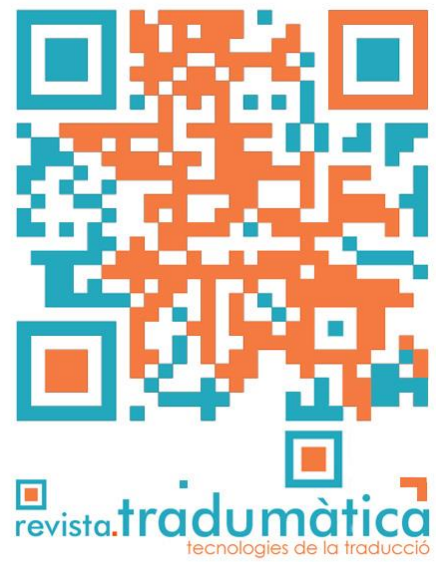

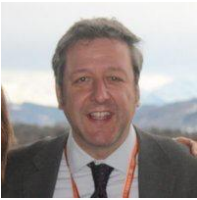

Rafael Porlán Moreno

Dpto. de Traducción e Interpretación, Lenguas Semíticas, Filología Francesa y Documentación, Universidad de Córdoba rafael.porlan@uco.es; ORCID: 0000-0002-2594-2593
Abstract

The use of portable sound equipment has grown rapidly in the conference interpretation market in the last few years, which has sometimes meant that it has been utilised in working environments ill-suited for interpreters to achieve the best performance possible.

Keywords: portable sound equipment, portable interpreting equipment (PIE), bidule, conference interpretation, whispered interpreting, consecutive interpreting, simultaneous interpreting

Resum

L'ús dels equipaments portàtils de so ha experimentat un creixement exponencial en el mercat de la interpretació al llarg dels darrers anys. Aquesta rapidesa ha provocat que, en alguns casos, aquest tipus d'equipaments s'utilitzessin en entorns que no reunien les millors condicions de treball perquè els intèrprets assolissin el màxim rendiment.

Paraules clau: equipament portàtil de so, equipament portàtil d'interpretació (EPI), bidule, interpretació de conferències, interpretació de xiuxiueig, interpretació consecutiva, interpretació simultània

Resumen

El uso de los equipos portátiles de sonido ha experimentado un crecimiento exponencial en el mercado de la interpretación en los últimos años. Dicha velocidad ha provocado que, en algunos casos, este tipo de equipos se utilizaran en entornos que no reunían las mejores condiciones de trabajo para que los intérpretes alcanzaran un rendimiento óptimo.

Palabras clave: $\quad$ equipo portátil de sonido, equipo portátil de interpretación (EPI), bidule, interpretación de conferencias, interpretación en susurro, interpretación consecutiva, interpretación simultánea

\section{Introduction}

With the advent of the 2008 economic crisis and the need for, on the one hand, conference interpreters to stay "afloat" in business and, on the other hand, for 
international conference organisers to continue providing customers with language services, a determined search for economic solutions began. Many conference interpreters reduced their fees, conference agendas were reduced in time to use half-day or minimum conference rates, some events either did not take place, or did without the provision of language services. The number of days of international conferences were reduced and employees of multinational companies were forced to learn English (Chaves: 2018) and stopped using interpreters. This context also led organisers to focus on the cost of sound equipment and sound engineering fees, as there was still a need for international communication:

The spread of new technologies has not replaced face-to-face communication. Rather, it has created additional communication opportunities, and this is in line with the communication needs in increasingly complex international and interdisciplinary projects requiring frequent, regular, fast and cheap communication contacts between the parties involved. (Braun: 2006: 2).

Despite the improvements in digital technologies, one of the solutions found did not mean resorting to a new high-tech, top-level audio-visual technology, but rather to an analogic sound emitting technology based on good, old-fashioned radiofrequencies, albeit with some restyling, namely portable interpreting equipment (PIE). Some 10 years ago, even if videoconferences enjoyed a certain level of popularity, phone rates were still high, so it was not the financial solution needed by companies and institutions attempting to reduce costs. Also, digital remote communication applications such as the various online interpreting applications now available in the market (e.g. from The Global Password, Language Line, Language Insight, etc.), were just sparkles in the eyes of startup managers. But portable equipment had been used for some time to assist in the interpretation of study or work visits, mainly in business settings. All this also poses issues in terms on interpreter training, as trainee interpreters should be aware of the different settings, environments and circumstances in which PIE's are currently used.

\subsection{A little bit of history}

It has already been mentioned that portable sets had been used for some time in the private sector when language assistance was needed in the case of visits to factories, farms, etc., but information about it is difficult to mine as it belongs to the area of interpreter's personal experiences. The first formal reference I have been able to find on the use of the equipment in an official setting is the one described by Shermet (2019). Apparently, a fellow interpreter, Roger Kaminker, had been in contact with technology while working at a private market assignment and thought that the newly elected Secretary General of the UN could be open to the use of portable equipment. So, in 2007, he "convinced the Chief Interpreter in Geneva to purchase one set on a trial basis", brought it with him on a mission to Africa and suggested the SG use it during bilateral meetings. Considering the time saved in terms of setup, it was seen as a major success. Now we may say that in the UN context, this kind of equipment has been used for some time in missions and conferences away from headquarters (Diur: 2015: 67). Given the aforementioned success, some bilateral meetings with the Secretary General at which consecutive interpreting $(\mathrm{Cl})$ was the standard of use are now handled with a portable solution. The current situation is that when work has to be carried out during 
field missions in difficult settings, or where no infrastructure is available, UN delegates prefer using mobile equipment (Diur: 2015: 67). Also, in some cases, even if simultaneous interpretation were the modality of choice, when there are only a few delegates participating in a mission and no more than one or two interpreters, for practical reasons whispered interpretation (WI) or the bidule are more frequently used (Diur: 2015: 199).

\section{A Theoretical Perspective}

If we were to define what interpreting with portable equipment is, we might say that it would be the development of an interpreting modality with the support of a portable sound system which comprises one or several microphones (for the main speaker and the interpreter) and receivers for the audience, and even for the interpreter themselves. I am referring to interpreting modalities because, depending on the skills the interpreter possesses and on the specific context, either simultaneous interpretation or consecutive interpreting can be used. Such precision is needed because standard reference books and manuals in the field of interpreting studies seem to define two clearly-cut working modes (Baxter, 2015: 2) or modalities. Although simultaneous would be the modality in most of the cases, there is no "prescription" regarding that, and both the speaker and the interpreter may feel more comfortable resorting to consecutive interpretation at certain times. So, an interpreting modality should not be confused with the resources used to put it to practice.

The most outstanding contribution to the understanding of portable equipment can perhaps be found in the initial few words that Setton and Dawrant use to refer to PIE in their course: "This [PIE] is also not a distinct mode, but refers to interpreting with minimal portable equipment" (2016:19).

Considering how the dynamics of WI can sometimes be hampered by the interpreter having to move about paying attention to where the listener or listeners are while trying to find the best sound conditions, it may be deducted that the use of PIE would come as a natural evolutionary step. According to Pöchhäcker:

While acoustic conditions make traditional whispering very strenuous, the use of "whispering" for small groups has been facilitated by portable equipment [...] that enables the interpreter to speak into a microphone and listeners to receive the interpretation via cordless headsets, ideally with the interpreter receiving the original speech via a headset as well (2009: 239).

From a different perspective, some authors land on a definition of interpreting with PIE by referring to it as "interpreting without a booth", while including WI also under such reference:

Occasionally, simultaneous interpreting can also be done without a booth. [...] In whispered interpretation, the interpreter sits next to or behind one or two participants and provides simultaneous interpretation in a quiet voice. When working with a bidule, on the other hand, the interpreter sits in the same room together with the participants and quietly speaks his/her interpretation of the speech into a hand-held microphone which transmits the interpretation to listeners who are wearing headsets. In that sense, working with the bidule is more or less like 
whispering except that the interpreter does not need to sit right next to the participants who requested interpretation (Diriker: 2015, 171-72).

So, on a positive note, fatigue on the side of the listener, as well as for the interpreter - who no longer needs to force their vocal chords to an unnaturally low tone of voice - has been alleviated for all participants.

Setton and Dawrant (2016:19) also refer to the poor reputation this kind of equipment has among interpreters, saying that it is "problematic [...] for obvious reasons of inadequate sound quality and acoustic isolation [...] and consequent impact on quality and interpreter fatigue, not to mention the voice of the interpreter distracting listeners who are not using the interpretation."

Following this line of thinking, it is very dangerous to consider bidule interpreting as a separate modality of interpretation, because it has led many clients to not take into account the original settings for which the portable equipment was conceived, and tend consider it as a cheap form of simultaneous interpretation. Even then, they will still demand from the interpreter the same quality - and lack of technical problems - which may be enjoyed at a conference using conventional interpreting booths. Of course, it does not help when some interpreters in their websites advertise their services mentioning that interpreting with bidule equipment is "a sort of portable booth".

Some authors anticipated how reluctant both interpreters and some organisers are to use PIE, as is the case of interpreting for the Olympic Movement: "Tour guide systems ("bidules") are never employed, and whispering only occasionally for languages that are not offered officially" (Hollstein, 2015: 99). This shows the extreme position adopted by some institutions, which may be presumed to be supported by their previous reluctance to use whispered interpretation.

\section{The equipment}

There are few references in the literature to the use of PIE, but there is plenty of online information sourced either by companies providing equipment rental services or by the users themselves, that is, the interpreters. For example, at the interpreting.info website, devoted to answering questions on this discipline, abundant information can be found on the advantages and disadvantages of using such equipment depending on the working environment. Also, the website of the International Association of Conference Interpreters (AllC) offers a certain number of entries regarding both the description of typical equipment and its technical characteristics, adequate conditions of use, etc.

The usual equipment is made up of the following:

- a portable case with a built-in power source and cells to store and charge each receiver;

- a variable number of receivers (from 10 up to around 100) (Guelbenzu, 2018);

- if possible, not one but a couple of microphones, one for the speaker to send their speech to the interpreter and another one for the interpreter to relay its 
interpretation to the audience; if in a room, such microphones would be independent from the ones connected to the room's PA system, if there is any;

- batteries for the microphones or speaker/interpreter emitters, microphone headset in the case of plug-in emitters;

- earphones for each receiver if they do not have integrated headphones; for reasons of hygiene, some companies offer either disposable covers for the foam covering the earpiece or disposable earphones.

The speakers' emitter should be configured in a different channel/frequency from that of the interpreter, so the audience is not bothered by having to listen to two voices at the same time. As portable equipment is usually adjusted by default to cover a limited number of frequencies, sometimes there are problems if other devices are using the same frequencies within a limited space. That can often happen in spaces with no frequency shielding, or where there are machines or other radio equipment emitting radio waves in the same frequency, up to the point of the interpreting equipment having its emission shut down. This is a real- and quite frequent - problem that clients should take into account when planning the use of this type of device and interpreting milieu.

Of course, PIEs offer clear advantages and this type of equipment has continued to evolve. At the time of writing this article, there are brands which offer transceptors included in the set (Guelbenzu, 2018). This means that both the speaker and the interpreter may speak and receive sound with the help of one single device. Usually, this technology also allows the audience to switch channels, so they may listen to the original sound as additional help if the environment is too noisy for them to follow the speaker directly. Another advantage this type of equipment entails is that, even if the setup can become quite complicated, additional languages may be included in the configuration. In other words, the speaker may use a language that is only understood by one of the interpreters, and an exchange/common language may be used by that interpreter so the rest of the team may in turn interpret into a tertiary language.

\section{Working environment}

\subsection{Interpreting modality}

As was pointed out at the beginning, depending on the setting, the interpreter can agree with either the organisers of the event or the speaker on the modality of interpretation to use. In the case of study/field visits, the speaker will probably expect to take shifts with the interpreter as is the case in consecutive interpretation. That may be the case if the interpreter is qualified in consecutive interpretation but does not have the needed command of simultaneous interpretation. Apart from that type of setting, most clients will expect the interpreter to resort to simultaneous interpretation, even if the working conditions resemble those of liaison interpreting (Guelbenzu, 2018). In any case, the interpreter must make very clear what can be expected from the modality agreed taking into account the local conditions. 


\subsection{Flexibility with regards time and location}

An advantage using PIE is that time may be used more productively than through the use of consecutive interpretation. Sometimes, if there is not enough space to set up a booth in a room, sound companies offer clients a CCTV system set up through which both image and sound are sent to a different space where the interpreters work. But that would still mean confining the audience to one single space. When setting up a booth is not possible for whatever reason, the organisers of an event may consider resorting to consecutive interpretation. But if portable equipment is available, consecutive interpreting may be chosen only if it is the preferred solution for other reasons, like a very small number of participants in the conversation, the will of the participants to use consecutive as a mean of making up for time and be able to reflect (as in international arbitrations), etc. It is obvious that interpreting simultaneously will save time compared to using consecutive interpreting.

There are more advantages to list: the organisers may change spaces according to the needs of the event (i.e. getting out from a factory plant and resuming the meeting in a conference room, or maybe using it at a board meeting with a limited number of participants) in no time, and choose a location which does not fulfil the ideal conditions a normal conference would require.

\subsection{Possible issues for the audience}

Regarding what can be expected by both the interpreters and the organisers, the whole team should be aware that the interpreter may be seen as an alien element in the meeting room. Even if finding a discreet place at the back of the conference room is possible for the interpreter, the backdrop humming noise of the interpretation can be a nuisance. As Baxter explicates (2015: 5) when referring to whispered interpretation, "it can cause an inconvenience to the surrounding public and not all situations offer the possibility of separating the interpreter's target public from the non-target public."

\subsection{Sound of quality}

Even sound companies (Gruppo Studio Busca, 2017) warn in their websites about what could be considered the standard use of portable equipment as compared to the setting up of a booth, and the possible drawbacks of using them in environments which are not really suitable for portable equipment. Interpreters may use such references to let clients know that what can be influential in their performance. As with regards the types of equipment, there are different levels of quality to be found among the various brands offering PIE solutions. Interpreters and sound companies may help by each agreeing on those which offer best results.

\subsection{The lack of a booth as a protective element}

For the interpreter, not counting on the protection provided by the booth panels may be a negative factor. Apart from reducing undesired noise both from the room for the interpreter and for the audience regarding interpreter's speech, there is a psychological 
component to be taken into account. Not counting on the panels as a divide between the interpreter and the audience/room reduces the perceived security the interpreter enjoys in the booth. In addition to that, in many cases interpreters may not have access to a table for their own working convenience while taking notes or checking information in a laptop or tablet through the internet.

Not counting on the protection of the booth increases the difficulty for the interpreter to focus. It is not just the noise problem or having to depend on equipment which does not always offer a consistent sound quality, but also having to take care of a changeable environment without a sound engineer to cover up for that. The booth creates a feeling of security for the interpreter: they may work from a protected environment, from some kind of a "bubble" where the interpreter acts as the "conductor" of their own work. On the above, Diriker also says:

Working in the absence of [...] soundproof booths, however, can be very taxing for interpreters. Interpreting in a proper booth gives interpreters control over the amplitude of the incoming sound and this enables them to strike an optimum balance between listening, speaking and monitoring their output. [...] Furthermore, when whispering or using the bidule, the interpreter must control his/her voice and keep it low at all times to avoid distracting the other participants in the room. For these reasons, these modes of interpreting [..] are generally regarded as exceptions to the common practice of interpreting in soundproof booths (2015: 171).

Finally, that the booth also acts as an environment of confidentiality (Guelbenzu, 2019). Anyone may peep into the interpreter's laptop, notes, printed documents provided to them by the speaker, etc., and comments made between the working pair may be heard by unwanted listeners.

\subsection{How to ensure adequate working conditions}

I have already stated that interpreters should agree with their client beforehand which modality of interpreting would be used with the PIE in order to avoid misunderstandings, but there are additional aspects which should be considered. With a PIE, the interpreter should always take into account the issue of sound quality. Let's review different environments and influential factors:

- Visiting a factory with functioning machinery can be a true challenge if noise conditions are extreme. This may be alleviated if all headphones provide good isolation, but it could be agreed to begin with delivering the core of the information prior to entering the facilities, and maybe some conclusions at the end.

- Working outdoors involves monitoring the range of the equipment so that neither the interpreter loses the signal from the speaker's emitter, nor the audience loses the interpreter's signal.

- Quite a different environment is that in which the interpreter's audience remain seated in a room because the organiser considers that using a portable equipment would save a decent amount of money. The organiser might deem it possible for the interpreter to use the sound coming out of the room's loudspeakers as the 
original sound source, but that is not an acceptable solution. In fact, the AllC's Code of Ethics states under article 7 that members of the Association:

d) shall not agree to undertake either simultaneous interpretation without a booth or whispered interpretation unless the circumstances are exceptional and the quality of interpretation work is not thereby impaired;

In fact, the full-room and PIE type of configuration mainly poses different types of problems to cope with:

- It is only with a full room and with all sound equipment functioning (and this includes the PA system of the room as well) that the interpreter will realise if they are in the best conditions to perform well. As a start, the interpreter should place themself as close as possible to the speaker, maintaining a body posture which would let them listen to them with as much clarity as possible.

- If located in a room equipped with a PA system, the sound from the loudspeakers may not be enough for the interpreter to follow while interpreting simultaneously and coping with self-monitoring, and there can be noise in the room which would hamper the interpreter's ability to follow the speeches; a discreet visit to the working room some time beforehand can prevent the interpreter from suffering many a headache;

- In good faith, the organiser may invite the interpreter to take a seat beside the speaker, believing that it would be the best place to follow the speech. That can be true in a room with no sound equipment, where the voice is going to be heard in a natural environment, with no artificial echoes. But this will backlash in rooms equipped with a microphone and loudspeakers: the sound will be projected from the stage towards the audience, and the stage itself would be the worst place to hear anything. In such cases, the best place for the interpreter would be in first row of seats of the stalls. Once again, an additional microphone for the speaker to send an exclusive signal to a set of headphones for the interpreter will minimise sound hearing problems.

- As Magalhães (2016) states, in a sound setting where several microphones are connected to the sound mixing board, there is always the possibility of connecting a transmitter which could send the exact sound quality offered by the board to the interpreter's receiver.

- The interpreter will be focused on their work, will not be protected by any booth's panels and may be speaking louder than in a normal conversation, not aware of the actual sound level generated. As said earlier, this can be very disturbing to any members of the audience sitting nearby.

- In order to solve the problem of bothering the audience with the interpreter's rendition, one possible solution could be for the interpreter to sit at the back end of the room, wherever there is an empty space or enough room between the interpreter and the audience. Of course, PR abilities and a fluent communication with both the organiser and the audience is a must in order 
to gain the understanding of all of them, always using the argument that small reorganisation arrangements will improve the quality of communication.

It should also be remembered that, as mentioned above, not all equipment offers the right quality. Accordingly, the working conditions may vary dramatically. Some rental companies still offer old sets which for the interpreter mean "long hours of standing and poor sound quality" (Magalhães, 2016) - although this can also happen when interpreting in a booth. As old devices would not include a microphone for the speaker, the interpreter would have to chase one or several speakers around a room to make the most of natural hearing. With crystal clear sound available and the interpreter able to sit wherever they deem most appropriate, this "pilgrimage" should not be a problem. If no decent conditions are met in the end, it might be the type of assignment or environment where a clear "no" by the interpreter will probably be met with a satisfactory response in terms of the election of a different brand name or model.

\section{What the current situation looks like}

Whatever the advantages or disadvantages PIE pose, one must admit that the use of these systems has become increasingly popular with international organisations (Magalhães, 2016), especially when the physical infrastructure does not allow for the setup of a full booth nor a CCTV installation.

\subsection{Should interpreters defend some caveats?}

The spread of the use of PIE's should make interpreters aware of when to demand minimum working conditions and when to simply say "no". Let's exemplify this with some cases:

- The client or the person responsible for an event might be of the opinion that the interpreter should do their work and take care of any technical issues affecting the equipment. The client should then be made aware that if they assume that the interpreter should take charge of setting up channels, replacing a receiver which run out of battery or offering faulty sound, etc., they must stop working and maybe lose focus. Sometimes, the intermediary (i.e. the event organiser helping the original customer with the setup of the conference) will even expect the interpreter to be in charge of transporting the equipment to the venue and delivering the individual receptors to the audience. That should never be considered a mandatory task for the professional.

- Apart from putting logical provisions in place, such as looking for a good quality equipment - in case of assuming the responsibility of offering it -, or warning about the limitations of PIE equipment in a contract or warning document, the interpreter must be ready to defend themself in case the speaker does not use the microphone correctly, or if someone fails to keep their earphones plugged in or to merely start their receiver. 
- A stern warning regarding how the quality of sound will never be that of a boothed interpreting environment should also be a must, as that is bound to influence the quality of the interpretation considering the extra stress - and effort -involved in the processing (Gile, 1995) of a speech affected by poor sound conditions.

- It must be said that the use of this system does not justify reducing the number of interpreters in the team (at least two interpreters for two languages) (Keil, 2011), not that it means a cheap version of simultaneous interpretation with a booth, nor an excuse not to learn or practise consecutive interpretation (Guelbenzu, 2012). When drafting a quote for a prospective client, who may not be aware of the relationship between effort and the specific technical resources needed in interpretation, elements such as these one should appear clearly stated.

As early as 1991, the (AllC) devoted a special document (the "Text on bidule") to the use of portable equipment "without a booth". The last available version of that document (2002) includes a series of criteria which should be met if this equipment is used:

- special circumstances: visits to factories, hospitals and environments posing special difficulties or whose nature hampers the use of traditional booth interpreting;

- short meetings (2 hours, for example);

- limited number of participants (maybe a dozen);

- two-way equipment (i.e. 2 transmission channels and one from interpreters to participants, the other from speakers' microphones (essential) to interpreters' earphones;

- compliance of such equipment with IEC914 standard.

It is not by chance that some researchers have found close similarities between telephone interpretation and bidule interpreting in terms of the problems interpreters found, and regarding how the quality of interpreting and the working conditions may be negatively affected. For example, in an Australian survey on telephone interpretation (Wang, 2018) some respondents complained about it "being used in inappropriate situations" and how "they preferred on-site interpreting to telephone interpreting". Something else may also be used from Wang's paper in terms of having interpreting quality as the final aim: the conclusion that both interpreters, clients and interpreter employers need to work together to improve the quality of the service (Wang, 2018: 2). Another usable proposal would be developing national and international protocols for telephone (or PIE) interpreting; national protocols could be agreed with conference organisers' associations as well as with the public institutions which make regular use of these services.

As a final note in this section, I would like to quote Magalhães (2016) words:

[the use of the bidule] It is not supposed to question the value of good consecutive interpretation at high-level diplomatic or commercial bilateral meetings. [...] As a conscientious interpreter you must continue to enforce the fine working conditions our profession has fought 
so hard to establish, especially with regard to manning strength and workload. No equipment in the world should replace that.

So, there is a real need for interpreter's training to include, at least in the latest stage, exposure to recent forms of doing interpreting such as this one, and maybe telephone interpreting in order to both prepare students for them and help them learn to avoid unpleasant situations.

\subsection{Does using portable equipment require specialised training?}

A list of needs and problems have been listed, which need to be taken into account if PIE is to be used. With regards to the teaching side, even if most of the basic techniques needed for dealing with an interpreting assignment supported on the use of portable equipment should be covered by regular conference interpretation courses. It is true that this is one of the settings where trainers/teachers should put emphasis on the importance of the working conditions.

That said, although standard interpreting techniques should suffice, unseasoned interpreters attempting to tackle a consecutive interpreting service may find themselves horrified at having to cope with a hard-core, poorly-adapted simultaneous interpreting service. Visiting a factory plant, keeping an eye both on the shop manager and on the clients at the same time can be really hard while trying to capture the contents delivered. Possible noise, loss of eye contact with the visit guide - who may forget that the interpreter should be following them both physically and cognitively - mean that the interpreter may see themself having to deal with the natural speech speed of the guide and far from an adequate environment: "[...] since continuously changing working conditions make it increasingly difficult for interpreters to work under the same or very similar conditions for a long period of time" (Braun, 2006: 2). The issue of adaptation and adaptability (Braun, 2006: 2) takes the front line here. The classical choice some very apt conference interpreters would make between consecutive or simultaneous interpreting becomes blurred here. There is no set environment, no static sound equipment and booth protecting the interpreter from eventual whims of the client or from a sudden change in the communication setting (i.e. the client group becoming reduced after a shift in the day's agenda and a possible change of the conference room, a problem with the equipment running out of batteries, or the interpreter's microphone itself drying out, etc.).

Can interpreters be trained to deal with the conditions described? Although it is quite difficult to represent those in the academic environment, mock commercial visits in which PIE is used, like the ones I have been doing at the University of Cordoba, may be quite representative of what lies ahead for students. There is no point in programming such visits too early in the curriculum, as students would still be too focused in the training of basic interpreting skills, but once the initial tests are close in the calendar, they can help them make up an idea of what interpreted visits are like while boosting their confidence in a near-to-real environment. At the beginning we did not count on any equipment we could use, but our Department was able to acquire a full set (2 microphones, 2 emitters and 40 receivers) through a European grant some years ago. 
A study is in progress process through which I plan to check student's impressions regarding these visits both with and without the help of portable equipment. Preliminary results show a) that our students feel much more responsible for their performance when set in this type of environment and with their class mates having to follow their interpretation; b) that the preparation effort (drawing terminology lists, reading materials on the type of industry the visit will be about) is really worth doing, as they may see immediate results in terms of good or bad performance; and c) that interpreting "dawns" in their minds as something they can professionally do in the future, even if not in the conference interpretation environment. Also, initial queries made to the teaching staff of different faculties where interpreting is taught in Spain show that PIE's are either not owned by the faculties or they are not used for visits but at mock international conferences. This last issue may be dangerous, as it could perpetuate the idea among future interpreters that the bidule may be perfect for simultaneous interpretation without a booth.

Finally, the business side of bidule interpreting could also be explored with students: conditions to include in a contract, possible warnings with regards sound quality and working environment, setting up a team with enough interpreters depending on the day's agenda, etc.

\section{Conclusions}

Interpretation with PIE systems is the right solution for small groups, visits and environments which make it difficult to set up traditional simultaneous interpretation booths and systems. Even so, their use has been stretched to the point of placing interpreters in dire situations for which the equipment was never designed. Interpreter training programmes and interpreter's associations should make clear which environments are adequate for using the bidule and the difficulties it entails. In sum, interpreters should refrain from accepting certain jobs if conditions for the use of a PIE are not suitable; a good communication policy with clients on how interpreting works, and on the circumstances which allow for making the most of such equipment is very much needed even at the present time.

\section{Acknowledgements}

I would like to thank my interpreting colleague Clara Guelbenzu for her kind help with regards the location of additional information on the use of portable interpreting equipment.

\section{References}

AllC (2002). Text on bidule. Al/C.net. https://aiic.net/page/633/text-on-bidule/lang/1.

- (2012). AllC statistics: Summary of the 2012 report. Al/C.net https://aiic.net/page/6878/aiic-statistics-summary-of-the-2012-report/lang/1. 
- (2014). Basic Texts. Code of professional ethics. A//C.net. http://aiic.net/p/6724.

Baxter, R. N. (2015). A discussion of chuchotage and boothless simultaneous as marginal and unorthodox interpreting modes. The Translator, v. 22, pp. 59-71. https://doi.org/10.1080/13556509.2015.1072614

Braun, S. (2006). Multimedia communication technologies and their impact on interpreting, in: Gerzymisch-Arbogast, H. (ed.). Proceedings of the Marie Curie Euroconferences MuTra: Audiovisual Translation Scenarios, Copenhagen, 1-5 May 2006.

http://www.euroconferences.info/proceedings/2006_Proceedings/2006_proceedings.ht $\mathrm{ml}$

Chaves, S.G. (2018). Remote Simultaneous Interpreting: The Upside and Downside, in: The ATA Chronicle. https://www.ata-chronicle.online

Diriker, E. (2015). Conference interpreting, in: Mikkelson, H.; Jourdenais, R. (eds.). The Routledge Handbook of Interpreting. London \& New York: Routledge, pp. 171-172.

Diur, M. (2015). Interpreting at the United Nations: an empirical study on the Language Competitive Examination (LCE) [Tesis doctoral]. http://rio.upo.es/xmlui/handle/10433/2145

Gile, D. (1992). Basic Theoretical Components in Interpreter and Translator Training, in: Dollerup, C.; oddegaard, A. (eds.). Teaching Translation and Interpreting: Training, Talent and Experience. Amsterdam: John Benjamins. https://doi.org/10.1075/z.56.29gil

Gruppo Studio Busca (2017). The "bidule" system: light interpreting - unobtrusive and versatile. https://www.sbservizi.com/en/blog/post/8/the\%E2\%80\%9Cbidule\%E2\%80\%9D-system-light-interpreting-\%E2\%80\%93-unobtrusiveand-versatile

Guelbenzu, C. (2012). Sistemas de interpretación portátiles. https://bootheando.com/2012/05/17/sistemas-de-interpretacion-portatiles/.

Guelbenzu, C. (2018). Usos y abusos del sistema Infoport. Online presentation, website of ASETRAD (Asociación Española de Traductores, Correctores e Intérpretes). Slide presentation and notes provided by the author.

Guelbenzu, C. (2019). Personal conversations held through e-mail through 2019.

Hollstein, S. (2015). Olympic Interpreting: a Guide to the Olympic Movement for Conference Interpreters. Master dissertation, Univ. Genève. http://archiveouverte.unige.ch/unige: 75177

Keil, A. (2011). Answer to "When to use an infoport system, better known as "bidule". http://interpreting.info/questions/284/when-to-use-an-infoport-system-better-knownas-bidule.

Magalhães, E. (2016). Portable Interpretation Equipment: What to Get and Why. https://ewandro.com/portable/. 
Moser, Peter (1996). Expectations of Users of Conference Interpretation. Interpreting, v. 1, n. 2, pp. 145-78. https://doi.org/10.1075/intp.1.2.01mos

Pöchhäcker, F. (2009). Issues in interpreting studies, in: Munday, J. (ed). The Routledge Companion to Translation Studies Routledge. Revised edition. London \& New York: Routledge, pp. 128-140.

http://translationindustry.ir/uploads/pdf/translation\%20studies-2009.pdf

Setton, R.; Dawrant, A. (2016). Conference Interpreting: A Complete Course. New York: John Benjamins. https://doi.org/10.1075/btl.120

Sermet, S. (2019). A story of innovation at the UN as told by the sidekick. ATA Interpreters Division. http://www.ata-divisions.org/ID/a-quieter-revolution-in-diplomaticinterpretation/

Wang, J. (2018). Telephone interpreting should be used only as a last resort. Interpreters' perceptions of the suitability, remuneration and quality of telephone interpreting. Perspectives, v. 26, p. 1, pp. 100-116. https://doi.org/10.1080/0907676X.2017.1321025 